\title{
FROM COMMUNITIES OF PRACTICE TO EPISTEMIC COMMUNITIES: HEALTH MOBILIZATIONS ON THE INTERNET
}

\author{
Madeleine Akrich (MINES ParisTech)
}

This is the post-print version of a paper published in Sociological Reserach Online : Akrich, M. (2010) From communities of Practice to Epistemic Communities: Health Mobilizations on the Internet, Sociological Research Online, 15, 2.

\section{INTRODUCTION}

In 2004, Phil Brown and his colleagues have put forward the idea that new patient and user movements - what they called 'Embodied Health Movements' (EHM) - had appeared in the world of health care next to older movements fighting for access to care or against inequality and discrimination, whether related to race, ethnicity, gender, class, and/or sexual orientation. These EHM are defined by three main characteristics:

They introduce the biological body to social movements in central ways, especially in terms of the embodied experience of people who have the disease. $(\ldots)$ practice $(\ldots)$

[they] include challenges to existing medical/scientific knowledge and

[they] often involve activists collaborating with scientists and health professionals in pursuing treatment, prevention, research and expanded funding. (Brown et al., 2004) (p.55)

From the authors' perspective, EHMs are mainly formed around environmental health issues or poorly identified diseases whose aetiology is not established. In the last configuration, patients often face skepticism from the medical world, which is tempted to relate their symptoms to psychological causes. To obtain recognition of their conditions and to have research conducted, patients become involved in collecting data and attracting researchers (Arksey (1994); Dumit (2006)). The experience they mobilize is more individual, bodily, and provides a basis on which new knowledge can be built. Furthermore, patients' relationship to medical science is ambivalent: if they criticize it, it is to better tame it for progress in medical knowledge appears as the basic condition to improve their fate. In what follows, we will show that the mobilization of individual experience as an alternative to medical knowledge, is not only limited to movements focused on poorly identified pathologies.

We know that in France, patient or user associations have emerged from focus groups and forums on the Internet. After several years of functioning, a subset of people who are particularly invested in the groups decide to change to another form of action: no statistics are available, but this phenomenon can be observed on health issues as diverse as cancer, autism, caesarean section, endometriosis, ADHD (Attention Deficit Hyperactivity Disorder), childbirth, Parkinson's disease etc. Browsing through the websites of some of these associations, one notes that research and literature occupy a prominent place in their concerns. Hence the twin assumptions we make: 
- as suggested above, far from being a phenomenon confined to specific health problems, the relationship between personal experience and formal knowledge is found in numerous dissimilar movements;

- electronic forms of interpersonal communication such as discussion lists or forums are probably a good place to observe the work done to articulate personal and formal knowledge.

Put differently, we might witness an emergence of new forms of politicisation, that rely on specific work destined to link personal experience and formalised knowledge, work made possible via electronic media.

The argument which we will develop is based upon a framework laid out by the social studies of science. First of all, we will highlight the processes through which knowledge and expertise is produced by laypersons. The notions of 'lay knowledge' and 'lay expertise', to which we will come back in more detail later, are increasingly used to account for the way personal experience is translated and mobilized in encounters between individuals, citizens' groups, researchers and experts or policy makers. While 'lay knowledge' refers to knowledge stemming from experience - in the case of a disease, knowledge that the sick person has of his or her disease -, 'lay expertise' rather depicts the result of the appropriation of scientific knowledge by laypeople. An emblematic case for the latter are the movements around AIDS that were able to intervene, by means of their expertise, on the definition of clinical trials and protocols for treatment (Barbot (2002); Epstein (1995)). These two notions seem central for an analysis of the back- and-forth movements between confined research and research in the wild (to take the terminology proposed by Callon et al. (2009)). However, the process by which this 'lay knowledge' and this 'lay expertise' develop is rarely described, partly because of empirical difficulties: our contribution aims to fill this gap by drawing upon a particular electronic form, discussion lists, which allow us to overcome this difficulty. Second, our approach seeks to describe electronic mediation in all its thickness: whether the movement analyzed originates in forums or discussion lists is not without its significance; certain characteristics of these media can be directly related to the manner in which these groups constitute themselves and interact, as well as upon the nature of what they produce.

Beyond this general frame, we will mobilise two areas of work, the first one centred on the notion of 'community of practice', the second one on the notion of 'epistemic community'. The first of these notions will permit us to describe and characterise Internet groups that bring together concerned people around a common heath issue; as for the concept of epistemic community, it will be used to account for the particular forms of activism that develop out of these groups.

Our analysis will be mainly based on mailing list archives: in previous work (Akrich \& Méadel (2002, 2007)) we collected messages from approximately thirty discussion lists relating to health topics, some involving professionals caretakers, others patients or health care users. In this article, we will focus specifically on a set of discussion lists covering topics related to the perinatal period, while occasionally mobilizing elements from other lists.

The paper is divided into two major parts. To begin we will characterise the way the discussion lists work. We will show that they can be considered as communities of practice (Lave \& Wenger (1991)) i.e. as spaces in which collective learning takes place. This learning process makes it possible, by comparing people's experiences to one another and to other types of knowledge, to constitute experiential knowledge and the building collective expertise. In particular, the connections between individual experiences and their relationship to scientific data and health care management are extensively analysed, and, drawing upon 
this analysis, an informed criticism is elaborated. In some cases, this expertise and/or the tools on which this criticism is based may be subject to publicisation, namely via a website, initiating a form of policy work.

In the second part, we will reflect on the activist movements emerging from these lists. We will see why these movements are a continuation of the groups that generated them, namely by the way they define their objectives, the type of work they undertake, their collective operating mode, and the cognitive resources on which they are based. This results in a model of activism that is somewhat different from the model described for EHMs, although experience and science are its major components: scientific knowledge is not a means by which people can expect to improve their living conditions or receive acknowledgment for their prejudice, it is the main resource on which activists rely to assert their views in front of physicians and policy makers. To describe these movements, we will call upon the notion of epistemic communities such as defined by Haas (1992b), i.e. a network of actors who share policy orientations in the sense of a certain definition of the problems at stake along with possible ways of solving them and a technical or scientific expertise that forms the basic argumentation on which these policy proposals must be based. This will lead us to extend this concept and question the modalities through which such epistemic communities come to emerge.

The article aims to shed light on several issues. It uses communities of practice and epistemic communities as support for an argument centred on the analysis of new forms of politicisation. These notions, transported from one context of application to another, will allow us to forge links between these different contexts. But at the same time, this shift effects the notions themselves, leading us to re-work them. In parallel, our analysis aims to describe the emergence of new activist movements in the field of health; we will characterize the manner in which they construct their claims and position themselves in relation to the medical milieu. Finally, the article seeks to revisit relations between 'lay knowledge' and 'lay expertise'; we will see how these relations are partly being redefined thanks to the new possibilities offered by the Internet.

Analysing discussion lists or forums is anything but straightforward: one has to deal with a corpus of several thousand, even tens of thousands of messages. Work that has been done on this type of material tends to privilege content analysis, an approach which obliges the analyst to concentrate on a very small sample of messages. Moreover, this approach does not capture the dynamics of the group. For example, the intensity of participation differs considerably between participants. In this analysis, we have drawn on a variety of methods, combining quantitative and qualitative approaches.

Preliminary work on the lists allowed us to: monitor the dynamics of exchanges over time; measure their subscribers' participation; assess the collective nature of the discussions (i.e. how many people intervene on each thread of a discussion); to identify certain persons whose participation is particularly noteworthy, either because they contribute greatly to the exchanges, or because they have a certain ability to initiate topics around which the collective discussion will prove to be rich. ${ }^{1}$

The use of search functions allowed us to select a corpus of messages that contained a particular word, or a particular expression. From this selection, we carried out statistical

1 This analysis is based on message headers that permit us to identify the date of the message, its author, its subject, and to identify the first post on a thread. No content analysis has been done. 
analyses to assess the importance of a theme within the discussions, and/or conducted content analysis.

Finally, these approaches 'at distance' were complemented by interviews with people who have created or moderated lists, or with participants (around ten in the case of perinatality) and the author's active participation to one of the lists.

This mix of methods is a requirement related to the topic at hand; in fact, the topic calls for both an overall characterisation of the activities of these lists and their way of functioning, and to examine in detail the discussions in order to understand the formation of these new movements and the knowledge on which they rely.

\section{COMMUNITIES OF PRACTICE, COMMUNITIES OF EXPERIENCE}

The concept of communities of practice was established to account for learning and knowledge construction modalities, which are usually neglected: learning is often believed to be the internalization of external knowledge by an individual, an interpretation that is based on a narrow definition of knowledge. In contrast, for Lave and Wenger, knowledge is created out of a dialogue between people's tacit and explicit knowledge, they insist on the embodied, distributed, trans-human and pragmatic nature of knowledge generation: knowledge production takes place within relatively autonomous informal groups, "communities of practice", made of people who are engaged in similar activities and communicate regularly on these activities.

Activities, tasks, functions, and understandings do not exist in isolation; they are part of broader systems of relations in which they have meaning. These systems of relations arise out of and are reproduced and developed within social communities, which are in part systems of relations among persons. The person is defined by as well as defines these relations. Learning thus implies becoming a different person with respect to the possibilities enabled by these systems of relations. To ignore this aspect is to overlook the fact that learning involves the construction of identities. (Lave \& Wenger (1991:53).

Whereas at first, Lave and Wenger were interested in areas in which formal knowledge played a role (butchers, quartermasters in the Navy, midwives, tailors, alcoholics anonymous), Amin \& Cohendet (2004) extended the use of this concept to activities such as research and to fields such as business, hence combining the anthropology of learning with, among other things, the sociology of science and innovation ${ }^{2}$. To us, characterizing communities of practice seems to revolve around three characteristics, which we will consider successively:

- a shared definition of what constitutes the basis of the group

- intensity and simplicity in mutual relationships

\footnotetext{
${ }^{2}$ They suggested, in particular, a concept of epistemic community, which does not take in the definition formulated by Haas and his colleagues: an epistemic community is, to them, a community of practice characterized by an explicit knowledge production objective and a number of organizational features related to its objective (nature of the mechanisms that make possible resolving disputes and establishing the validity of the knowledge produced). Please note, for the clarity of the argument, that this is not the definition of epistemic community we will retain here.
} 
- the existence of common "objects" elaborated implicitly - some kind of products derived from these exchanges- or, more explicitly, objects supporting and transforming the group and/or the individuals within the group.

The groups on which we focused were formed around a common experience related to health: it may consist in having lived through a disease, an important physiological process such as pregnancy or childbirth or having a special way to consider one's health and, for instance, calling on alternative medicines. These groups are typically hosted by list servers that can be 'generalists', such as Yahoo's or more specialized. On each server, the list is briefly presented and this presentation is coupled with links allowing a user to register:

Here, we discuss strategies to manage patients' daily life and we talk about mainstream research. The group aims at being a space for friendliness and mutual support dedicated to patient care.

This French-speaking list is intended for exchanging information, points of view, thoughts, experiences... around childbirth and parenting.

[This] discussion forum is a collective chronique [diary/narrative] on autism in every day life: testimonials, analysis, documents, information and debates. Whether you are parents, people with autism, friends, professionals, scientists, teachers, politicians, individuals, students, doctors, pediatricians, psychiatrists, child psychiatrists, psychologists, occupational therapists, speech therapists, educators, nurses, artists and intellectuals, this forum is yours.

The purpose of the list is mutual support. It is a self-help and discussion space where everyone can express their fears, doubts and hopes.

Exchange, sharing, support and assistance are the keywords of these invitations to participate in these groups. The issue of accessing medical and scientific information also appears to be present: these lists aim to provide answers to questions raised by subscribers and to keep them abreast with knowledge development. At first glance, they seem to bear more resemblance to self help groups than to groups organized around a cause such as advocacy groups, groups engaged in a war against disease (Rabeharisoa \& Callon (2000)) or embodied health movements (Brown et al. (2004)). As in self help groups (Borkman (1999); Weiner (1994)), the people who founded the lists find their motivation in a difficult or in any case particular - personal experience, which has led them to feel that the medical world does not provide satisfactory answers to these types of problems. The point is not, in the first instance, to form a social movement to turn the claims into a public issue, but rather to equip individuals and make them stronger when facing a disease or physicians, or even to initiate a collective reflection on the necessary conditions for change. In quite a few cases, a website created by an individual to make available to others his/her experience, and/or the knowledge he/she has gathered has acted as a trigger: a few Internet users interested by the subject contacted him/her, a discussion had started and a decision was made afterwards to open this discussion to the outside world by setting up a discussion list on a server. For that reason, there appears to be a slight gap between the point which the people who took the initiative to create the list have reached in thinking about the subject and the words they use to invite others to participate: as we will see later, this gap is, in most cases, a dynamic component in these exchanges, although it can sometimes lead to conflicts or just cause the founders to disinvest a group that takes a different direction from the one they had anticipated (Akrich \& Méadel (forthcoming)). 
Unlike a forum, a discussion list forms a closed group (only registered users have access to the messages) in which individuals are clearly identified: even if they have usernames, they are used in addition to identification via their real names and surnames. In addition, a presentation ritual has rapidly become common practice: each newcomer has to write a paragraph explaining his/her motivation and the person's registration is often validated only once it has been approved by the moderator, or even by the entire group. This measure has sometimes been taken after incidents - i.e. messages from members of the list forwarded to people outside the list without the consent of their authors, or after repeatedly aggressive interventions - but it was re-appropriated by the group and discussed in a much more general way. The following text is part of a message that was automatically sent to any new subscriber to the childbirth list:

Created in the beginning of 2000 , this list has become, as messages were posted and discussions addressed, a private discussion space that was warm, respectful and friendly to some, and to others, a place where they felt free, where insubordination and impertinence were welcome...

This is why each application is submitted for approval to the list members. Therefore, we would be thankful if you kindly sent us a short introductory message we would send out to them, mentioning your full name. (...)

This presentation is for us a way to avoid anonymous - or even sometimes "voyeuristic" - participation, since everyone needs to feel confident to share personal ideas. (...)

We are especially interested in knowing what you expect from a discussion about childbirth, personally, and not only with a professional purpose...This is why the details of your professional life are of lesser importance, since everyone's participation is supposed to be based on their personal experience. This also means that even if you belong to a "childbirth" association, your inscription is personal and in your interventions, you are not supposed to represent anybody but yourself.

In this message, automatically sent to any person requesting his/her inclusion to a list dedicated to childbirth, a number of remarkable features are concentrated, which are partly reflected in other lists and could be summarized by the notion of personal commitment: the list itself has the purpose of gathering individuals who only speak on their own behalf and from their own experience, whatever it may be, and leave their professional and/or political ties behind: 'we expect our members to talk about what they are rather than what/whom they represent.', the group owner states. However, exchange is not restricted to evoking an intimate experience, it includes - as a right - an opportunity to express one's views towards medical practices and health care management. In this configuration, there is no room for people who deliberately disguise or conceal their identity: as noted by Baym (2000) in her analysis related to discussion groups and soap operas. Banning anonymity is connected to the nature of these exchanges, which focus on an interpretation process where personal references are constantly mobilized.

Certain discussions following presentations that were made on the list illustrate the significance of this 'model', while showing the permanent re-composition process to which it is subjected: for instance when, despite the injunction that was made to them, people introduce themselves above all as professionals, which leads to lively discussions along with an extensive exegesis of the introductory message or requests for clarification addressed to the person. Ultimately, the fact that the person ponders about open questions and does not 
seek to promote a model ${ }^{3}$ is important; all the more if that person is ready to contribute to the debate around these issues rather than using the group as an instrument of knowledge and appropriating it to his/her own advantage. The expectation of reciprocity is self-evident in most lists even though, given the differences in experiences, skills, resources and time invested, the existence of asymmetries in the exchange is obvious to all participants.

Through this debate and presentation method ${ }^{4}$, the group builds a shared identity for itself: building common objects of interests and a shared understanding of the purposes of the group and of appropriate forms of participation. For this reason, one can speak of an "on-line community" in a much more rigorous sense than currently understood: the term "community" comes to loose its specificity as it stands for the many arrangements made possible by information and communication technologies ${ }^{5}$.

Active discussion lists experience sustained exchanges, which do without niceties or introductory precautions. This fluidity is obviously related to the medium: the cost of entering a discussion is technically low. Messages can be short or long and can build on previous messages, which reduces the repetition and clarification work. The exchanges' - and the group's - continuity is somehow obvious: in most lists, explicit greetings only mark users' subscription to or departure from the group, i.e. their first appearance once they have registered, their unsubscription, when they leave for holidays or come back, everything happens as if people were dealing with a continuous conversation, the spatial continuity created by the string of messages substitutes itself to temporal continuity. There is no obligation to participate, and the conditions are conducive to forms of 'peripheral participation' (Lave \& Wenger (1991)), which allows newcomers to learn about the group and the way it works.

At first glance, one can consider that the production of common objects is co-substantial to the list's activity itself, insofar as the exchanges are done in a written, sustainable form and that the minimum 'production' unit is not the message, but the discussion which gives the message its meaning: from a certain point of view, one can even say that the 'community' only exists through the production of a collective discursive object, with the exception of a small number of physical encounters that allow a subset of participants to meet. The fact that elements from a previous discussion can be taken up weeks or months later attests to the role played by the corpus in the constitution of the group.

I am looking for old messages on the topic of the Bonapace Method. Yahoo's interface search engine provided no answers

An answer: According to my archives, we mentioned it on the list (many messages) between $4 / 2 / 02$ and $12 / 2 / 02$. It would take long to copy them all...

Regarding VBAC [vaginal birth after cesarean], you can read lots of things in the list's archives.

\footnotetext{
${ }^{3}$ For instance, on another list, in a dispute over the attitude of a member of the list: 'There is a difference between bearing a testimonial on one's lifestyle and principles (whether agreeing or not) and trying to impose one's point of view and manipulate newcomers by imposing one's principles through entire pages.'

${ }^{4}$ On the way newcomers' entries are handled by the group and contribute to weld the group see Méadel (2006).

${ }^{5}$ For criticism relating to this trend, see Kling (2003).
} 
Celine, temperature in itself is not dangerous. It is only when it goes up very quickly that it can make a person convulse. May I suggest you search the list archives? We have often mentioned this.

It's a subject we discussed in detail a few months ago, but it is recurring and it's important in my opinion...I think old messages can be located by looking for the word 'doula'....

However, the technical interface is often an obstacle to this appropriation of the corpus; the corpus has thus a limited capacity to serve as an object around which the group constitutes itself $^{6}$ : searching for messages and reconstituting discussions are strenuous tasks - the sociologist knows this better than anyone else. We will see below, though, that the lists have implemented a comprehensive strategy to circumvent these difficulties.

In sum, therefore, following the intuition expressed by Amin \& Roberts (2008) drawing upon Josefsson (2005), we have established that discussion lists demonstrate the same characteristics as communities of practice, as they were defined above: intense and continuous interactions perform a definition of the group at the same time as producing common objects that consolidate the group, supporting individuals and engaging them collectively in a process of transformation.

However, these communities of practice share some distinctive features we want to highlight by using the term 'community of experience' which helps to refine the notion: in doing so, we stress the fact that shared experience - defined both by a common experience all users have know and the fact that they are sharing this experience with others - forms the backdrop on which these exchanges are built.

\section{EXCHANGING EXPERIENCES: FROM THE INDIVIDUAL TO THE GROUP}

The sharing of experiences - which is put forward as one of the purposes of these lists represents a significant part of the messages but takes different forms: they can range from a fairly long life story - for instance when a person joins the list - to comments on the effects of certain treatments, the narration of specific events, whether they relate to relationships with doctors, relatives, colleagues, spouses or oneself, or an explanation of the way one is to manage a specific problem. These exchanges may be motivated by a need to communicate or seek comfort, but also by a need to be given opinions or advice. As a response to these requests, other experiences are reported, commented, re-analyzed by other participants, so that cross-learning arises from these individual experiences: a whole interpretation process begins - of course with the intent of helping people - but its impact goes far beyond that framework. Throughout these discussions, we can observe different 'versions' or ways to formulate the issue at stake, leading to formulations of what relationships between doctors and patients should be like; sometimes reading like 'moral codes' or 'ethical options'. For example, participants share the idea that the mother/ the parents, should be put center stage in all decisions regarding childbirth, this event being considered as a physiological event and not a medical one.

Apart from 'spontaneous' testimonials, we also observed specific calls to gather experiences, assuming that accumulated testimonials would provide a comprehensive vision of these issues.

\footnotetext{
${ }^{6}$ Technical developments were announced that could achieve some sort of hybridization between lists and forums and change things quite dramatically from that point of view.
} 
Is vaginal delivery after 2 caesareans necessarily hyper medicalized? tell me about your experiences.

Yesterday the gynaecologist wanted to see me again ... and then things were no longer going well. The baby's weight is estimated at approximately 4.100 $\mathrm{kg}$ and the BPD is $100 \mathrm{~mm}$... He said "l'm going to induce labor tomorrow." I am not a car you're supposed to take for a checkup... I was utterly shocked... (...) What do you think? I would appreciate your telling me about me your experiences...

And what about the vitamin $\mathrm{K}$ injection? What is usually done (when it is injected, on what part of the baby's body, etc. (...) and what about pain management? What are your experiences and the choices you made (injection, oral medication, neither one)? I have no idea...

The constitution of these 'corpuses' is subject to two types of motivation: above all, an individual wants to collect rich and diverse information allowing him/her to have an overview of the possible options and settle on the best choices and actions. In other cases, the collective - as an entity gathering individuals that are placed in similar situations and experience similar problems - is explicitly understood as the intended beneficiary of these actions A constant effort to articulate their individual experiences and build a form of generalization is at work. The transformation of experience into 'experiential knowledge' does not just happen: to Borkman (1976), 'experiential knowledge is truth learned from personal experience with a phenomenon rather than truth acquired by discursive reasoning, observation, or reflection on information provided by others' ( $p$. 446), and requires 'a complete mental grasp of the nature and significance' of what is involved. She differentiates between what is related to experiential information - 'isolated, unorganized bits of facts and feelings upon which a person has not reflected' (p. 447) - and the experiential knowledge that involves a form of reflexivity on one's own experience. Discussion lists appear as privileged spaces for the construction of this experiential knowledge: as in the self-help groups studied by Borkman, experiential information is shared through testimonials and stories told by participants, however the written form - all the more when it is digital - lends itself quite well to the development of collective reflexivity, especially through the intersection of comments, reconciliations, possible comparisons and the corpus constitution it allows.

\section{CONNECTING EXPERIENCE AND KNOWLEDGE}

Beyond these personal experience exchanges, the electronic format gives way to other possibilities through its ability to convey and/or to connect all sorts of messages, or even multimedia documents (audio interviews, videos). The circulation of texts produced outside the group - articles, position papers, informational documents, discussions within other circles (lists or forums) - is important, as evidenced by the following chart. 


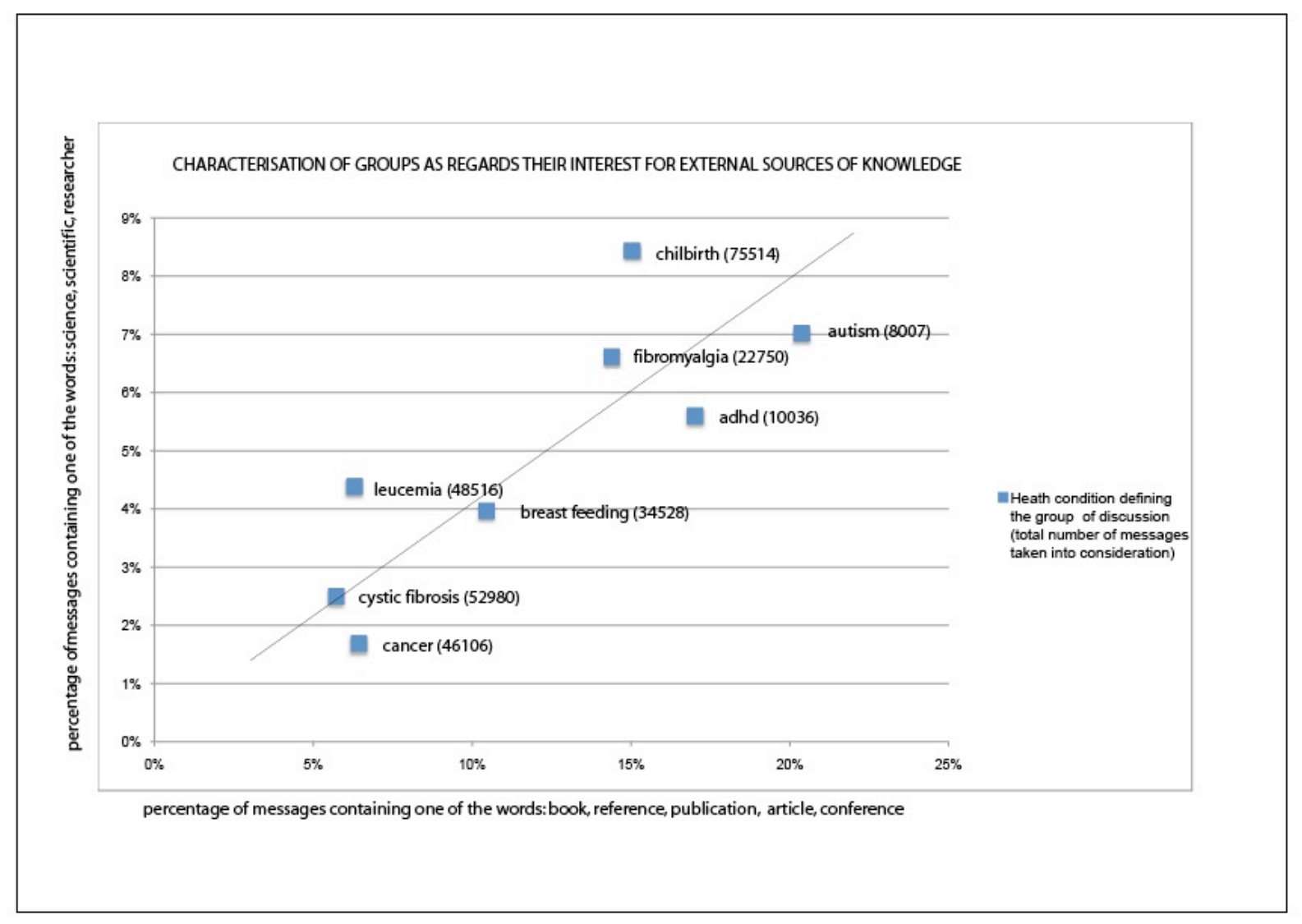

This graph was constructed as follows: for each list, we selected and counted messages that contained one of the following words: book, reference, publication, article, conference. These words refer to sources of knowledge that are external to the list. We then calculated the percentage that these messages represent when compared to the total number of messages of the list (indicated in-between brackets next to the theme of the list). This percentage, represented on the abscissa axis, varies between $5,7 \%$ and $20,4 \%$, and shows that the circulation of external references is quite important on the list. It is not rare for a participant to share his or her enthusiasm for a piece of work that is unrelated to the topic of the group. However, most of the items that circulate are publications, references, and announcements of events related to the topics of interest of the list. These may be accounts of experiences books with testimonies, websites, blogs, forums - articles in the mainstream press, books or articles which take a 'political' stance in a wider sense, but also, to a great extent, books with medical content and scientific articles.

To account for the part of the discussions that have a scientific content, we thereafter selected and counted all the messages that contained an explicit reference to the scientific world in the form of one of the following words: science, scientific, researcher. Then we calculated the percentage that these messages represent. This percentage, represented on the ordinate axis, varies between $1,7 \%$ and $8,4 \%$. One notes that there is a correlation between the interest of the members of a list for external sources of knowledge and their interest for scientific content.

On these lists, there is a more or less routine information transmission activity related to the latest scientific developments, to public policies, to the evolution of medical practices and treatments, etc. Certain participants play an informal role in providing a scientific and political watch, or even in translating, and their messages are more akin to a kind of uninterrupted column on issues that are likely to concern the other members of the list. In some cases - 
such as autism as described by Méadel (2006) - discussing these texts is one of the mechanisms by which the unity of the group is built, which is marked by a strong opposition to psychoanalytic theories.

However, the references to external sources are often included in the list's 'ordinary' ongoing discussions and contribute to this particular texture that characterizes electronic exchanges inextricably entangling registers that are often separate otherwise. The way this entanglement occurs is variable: in a number of cases, explicit quotes or references are produced as a response to a question. Information can also be provided to allay anxiety or reopen possibilities too swiftly excluded, for instance when a young woman in late pregnancy cannot imagine escaping caesarean if her baby refuses to turn over before delivery.

In other cases, an article or a book initiates a discussion in which individuals' experiences are reprocessed. On lists dedicated to unfamiliar diseases whose definition is controversial, international scientific literature circulates to a large extent: on a list of fibromyalgia sufferers for instance, $4 \%$ of the messages include the terms 'translation' or 'in English', and several members of the list provide a significant translation work as related to the articles intended for the list.

Finally, the discussion can progress by going back and forth between individual experiences, knowledge and even formalized 'political' implications in the broad sense ${ }^{7}$. This dynamic can be facilitated by the composition of the group: the fact that certain members, including the founding group, are carriers of a more or less critical query as to the medical world or health organization is a central element. The members' diversity is another: on the list around childbirth, the presence of a small number of professionals seriously questioning medical practices and people with an experience of foreign countries has greatly facilitated the articulation between individual experiences, 'scientific data' and statistics. On this list, a discussion on a medical procedure such as episiotomy combines testimonials from women about the consequences episiotomy has had on them, comparative data on practices as performed in various countries, data from the scientific literature, which leads to consider the singularity of French practices and therefore the grounds on which these practices are based: the organization of work in maternity wards, relationship to other obstetric practices including epidural analgesia and so on. A significant part of these exchanges thus appears as a collective investigation around the various ways individual experiences are problematized, and it is in the light of this problematization ${ }^{8}$ that individuals reconsider their own experiences. The connection between these elements is facilitated by the fact that the individual experience of a disease or process such as pregnancy or delivery (Akrich \& Pasveer 2004) is now inseparable from the methods established by medicine: they constitute both resources and constraints around which people's experiences - including their bodily

\footnotetext{
${ }^{7}$ Boland (1995) emphasizes the importance of narratives in the way communities of practice operate, in addition to 'paradigmatic' knowledge: the narrative mode is the mode that provides information on ordinary normativity since narratives are often built on moments during this normality is questioned. Learning abilities would be related to the possibility of connecting these different types of knowledge.

8 The founder of this list emphasizes this problematization dimension, which he matches against a 'problem-solving approach' Bel (2005).
} 
experiences - is built ${ }^{9}$. There is thus no clear-cut separation between experiential knowledge and formalized knowledge, or between lay knowledge and lay expertise ${ }^{10}$. Instead, we should rather assume that it is the entanglement of these two types of knowledge that permit nonprofessionals to make their voices heard and to render legitimate their claims when confronted with doctors eager to discredit their patients' claims on behalf of the authority conferred upon them by arguments based on scientific foundations.

These discussions are generally not very conclusive in terms of collective action: there, organizational learning is important but learning is more oriented toward individuals as it is in most communities of practice (Amin \& Cohendet 2004).

\section{FORMATTING EXPERIENCES AND KNOWLEDGE BASES}

Nevertheless, a number of exchanges can lead to 'products' that are isolated from the constant stream: they may basically be files made available to subscribers on the host's site, but lists frequently go much further in formalizing and externalizing a group's work, namely by building a space in which part of what has circulated and/or has been produced by the list is organized into a knowledge corpus ${ }^{11}$.

The childbirth portal - 'collective emanation from discussion lists', according to its initiators is a particularly rich example. The list owner had already built his personal website and, having computer skills, his establishing of such a portal appeared to be obvious once the list had existed for two years. Gradually, he stored all sorts of information on the portal, links to websites, a list of discussion groups, a directory gathering the organizations working in the field; he created an 'event' section, compiled a 'bibliography' (a list of books along with their abstracts), drafted 'fact sheets', built an 'article' page and assembled a corpus of childbirth narratives. We will turn now on these last two elements.

The 'article,12 page includes links towards hundreds of documents in full-text that are reported or even discussed on the list. These documents, classified by theme, are very diverse: academic theses, articles from mainstream newspapers, government reports, legal articles, conference papers, but also extracts from discussions, which in some way allow

${ }^{9}$ Analyzing a diabetes forum, Loader et al. (2002) came to a similar conclusion: 'Rather than a rejection of evidenced-based clinical advice, [the newsgroup] offers a secure space where such information can be assimilated and reflexively shaped to inform lifestyle choices - a space where discursive learning about one's condition can be undertaken on a more equal basis' (p. 64).

${ }^{10}$ However, connecting them requires a certain amount of work. In their article, Collins \& Evans (2002) are interested in similar issues to ours, but while their characterization of what we will call lay expertise is well developed, knowledge stemming from experience is hardly described and is somehow only relevant once it is translatable into the language of science, which causes this knowledge to lose much of its specificity.

${ }^{11}$ More rarely, designing tools intended for list participants - which aim at helping them to manage certain specific problems - such as, for instance, software to support medication monitoring for Parkinson sufferers (Akrich \& Méadel, 2002) or educational tools for parents with autistic children.

${ }^{12}$ http://wiki.naissance.asso.fr/pmwiki.php/Portail/Articles 
understanding a question by switching back and forth between personal experiences and more formal knowledge. For instance, the part concerning over-due terms ${ }^{13}$ starts with questions from a woman who is in that situation. In the exchanges that are reproduced here, stories emerge, and so do background information on current practices in different countries, statistics on post-term births, on birth weight as related to terms etc. In short, it is a sort of digest that does not belong to a well identified genre, but offers an overall prospect enabling users to embrace key points from the perspective of a person facing the problem in question, without prejudice to the practical conclusions that one can draw on a personal level: conceivably one should see in this type of document a form of experiential knowledge formalization that respects its profoundly hybrid nature. The list owner also explains this practice very clearly:

Discussion threads are persistent over years thanks to the storage of messages, and message databases (both on the list server and in recipients' mailboxes) may be searched via electronic queries. It is of great relevance to be able to trace a discussion thread from its very beginning and come back to the point at which a reader may have felt frustrated or offended by the turn of the debate. Previous messages are generally explicitly quoted for the sake of clarifying viewpoints. "Rewinding" time to review accurately a discussion thread would be impossible in a physical gathering. (Bel (2005)) p. 363.

Finally, the page makes available comments on a number of publications; these comments mostly stem from messages on the list or from letters sent to these documents' authors and their replies if any.

The 'narrative' page ${ }^{14}$ gathers over 60 childbirth stories, most of which were posted on the list on childbirth issues. The idea of publishing these stories first emerged from several members of the list's wish to share the pleasure and interest they had taken in reading them. In a brief lapse of time, the reflection went further; when the list owner mentioned his intention to upload a number of texts he has already selected, he sketched a narrative policy ${ }^{15}$.

Many other childbirth stories have circulated on this list - and their authors can ask us to publish them, anonymously or not, the best being to put them on other sites and only put the links on the portal. Because the more links we have and the better we can encourage our readers to visit other websites, to listen to other perspectives...

The question of determining the appropriate content to be included on the portal and its position in relation to the outside world are the subject of debates during which the group's self definition is questioned: it is not static, determined once and for all, it needs to be constantly tested and is liable to change over time. Thus, facing an association's application to appear on the site, the list owner writes:

These demands are, to us, an opportunity to reaffirm or reconsider our acceptance criteria. (...) Even if some of us do not identify with this association's strategy, we must not lose sight of two points:

\footnotetext{
${ }^{13}$ http://portail.naissance.asso.fr/liste/terme.htm

${ }^{14}$ http://wiki.naissance.asso.fr/pmwiki.php/Portail/RecitsDeNaissances

${ }^{15}$ Anglin (1997) describes another form of political narrative deployed by pioneers from U.S. breast cancer movements: by making their experiences public, they enabled breast cancer to become a political issue.
} 
1) The sites that are already listed represent a range of approaches that we do not all perceive the same way;

2) The site that is suggested clearly highlights a freedom of choice, with a way to conceive this freedom that is broader than that of many associations.

To someone who was asking whether 'the portal had (...) to be the reflection of each and every thought about Childbirth,' he further explained: 'No. It reflects "civic" approaches, i.e. approaches that favor information and freedom of choice.'

Through this publishing activity and the issues it raises, a political orientation 'in action' seems to appear, which is broadly articulated around knowledge production/dissemination. This orientation is not the result of a majority vote in the list, nor does it adopt the founder's or the dominant group's orientation, nor is the smallest common denominator among all possible orientations. It is, instead, the result of the way the group is composed, which refuses to let itself be reduced to one of its 'lines'. Similarly, exchanges are not reduced to the debates that are sometimes reproduced as such from the site and illustrate, by their very form, this aspiration to preserve the plurality of the voices and viewpoints.

Although the connection between the portal and the list is very strong, the website does not only represent the list, it acquires its own dynamics, which are more obviously open to collective action: 'Its objective is to revitalize parent and childbirth attendant association movements in French-speaking countries, making available to them new information, communication and promotional tools as well as documentary resources for free on the Internet', as the website presentation states.

Throughout this section, we have seen that discussion lists were collective learning spaces aimed at producing intelligibility and allowing each user to reopen the space of possibilities, not to find him/herself locked on the paths traced by the medical and institutional world. This intelligibility stems from the bridge built among individual experiences and between these experiences and a variety of further knowledges. The electronic medium proves to be particularly suitable for the circulation of these materials and their collective re-elaboration. A common culture of rational discussion and a series of arguments are built that are capable of articulating individual perspectives with science, law and policy standpoints.

Because discussion lists a-priori establish the group as a set of irreducible individualscontributors and do not provide any tool to aggregate individual positions, these communities of experience are geared toward individuals. Nevertheless, in a number of cases they eventually produce objects that are no longer part of the exchanges and somewhat formalize their contents. In the movement by which these objects are defined, organized and made public, a writer-actor is established, and therefore invested in a project and enrolled in a political process. We are now at the tipping point between communities of experience and epistemic communities, i.e. the point where the learning achieved within the lists, the accumulated facts, the experiential and built-up knowledge could become a form of political action.

\section{TOWARDS EPISTEMIC COMMUNITIES}

Haas suggested the concept of epistemic community to reflect the new ways in which policy coordination could be built around issues with strong technical and scientific uncertainties. Haas studied the process that led to the Montreal Protocol, prohibiting the chlorofluorocarbons (CFCs) involved in the development of the hole in the ozone layer: this decision was largely unforeseen a decade earlier when the problem emerged, as it went 
against national policies and industrial interests. One cannot even appeal to the elaboration of a conclusive scientific consensus concerning the causes of the ozone hole: at the time this decision was to be made, there still were major uncertainties on that issue. What happened then, that led to what is now considered a remarkable achievement?

According to Haas, an 'epistemic community' gradually formed around these problems and played a major role in the process: its members gathered information, conducted studies, tested hypotheses, reported results to policymakers and industrials, 'infiltrated' a number of government agencies, drafted policy proposals. In short, they simultaneously shaped the problem and its solutions. Not only did they prepare the political decision, but they also managed to articulate the scientific aspects along with political ones and to build networks that allowed them to impose a point of view. This is where the specificity of epistemic communities lies, that are characterized by a dual scientific and political positioning in the broadest sense of the term: thus, in the case of CFCs, the actors who mobilized around the ozone hole issue were specialists on the question in different ways and had in common a clear-cut environmental concern.

(Haas 1992b 21) defines epistemic communities as:

A network of professionals with recognized expertise and competence in a particular domain and an authoritative claim to policy-relevant knowledge within that domain or issue-area. (...) they 1) have a shared set of normative and principled beliefs ... 2) shared causal beliefs, which are derived from their analysis of practices leading or contributing to a central set of problems in their domain and which serve as the basis for elucidating the multiple linkages between policy actions and desired outcomes .... 3) shared notions of validity .... and 4) a common policy enterprise ... p.3

According to Haas, these communities become major players on the complex issues our societies are facing: they allow decisions to be made and possibly coordinated at different levels.

The notion of 'epistemic communities' rightly points to a transformation of the modalities through which public policies are developed: the center of gravity shifts from within administrations to actors who are external to these administrations and are caught in variable geometry networks. However, the way these communities are constituted and come to hold a hegemonic position remains quite obscure. For a number of authors, it is as if, from their establishment, epistemic communities were bound to succeed: when an improbable compromise is found on a complex issue, the existence of an epistemic community can be suspected. Similarly, the possibility of a clash between two epistemic communities is never considered: this is partly due to their ambiguous status. Indeed, they seem to be unable to emerge otherwise than to support a request from government bodies. In the case studied by Haas (1992a), the obstinate action of one of the directors of the United Nations for Environment who organized conferences, workshops, publications appeared to be central both in creating the community and in giving it a power of influence. However, a more liberal version of the concept is provided by Peterson (1992), including the possibility for activist groups to constitute an epistemic community.

We suggest the notion of epistemic community can be used to describe the network formed by a set of groups, having emerged from the list on childbirth issues, playing a role in the elaboration of childbirth policies. Unlike 'traditional' epistemic communities, these groups do not a-priori have recognized expertise; their members, as a majority, are not perinatal professionals. 
The epistemic community we will describe has emerged through a number of initiatives instigated by the 'childbirth' list; some of which we show below. We observe that mailing lists were created for mutual support on issues such as caesarean section or episiotomy, but to deal with more political topics other lists emerge. There is a list on birthing centers, a particularly hot topic in France. Alongside, three associations were created - we will come back to them later - and various information tools, websites and newsletters. The movement that had started when members of the 'childbirth' list put the contents of their exchanges online rapidly amplified ${ }^{16}$ through these new activities and groups: while preserving its support and exchange dimension, they seemed to be making a move towards more traditional forms of commitment.

\footnotetext{
${ }^{16}$ Its owner, disappointed by the fact that the reflexive dimension - strongly present when the list was created - seemed to have dried up, giving way to consensual and self-centered exchanges, closed the 'childbirth' list in May 2007. The investment of some list members in other activities and communities may be a factor explaining this evolution.
} 


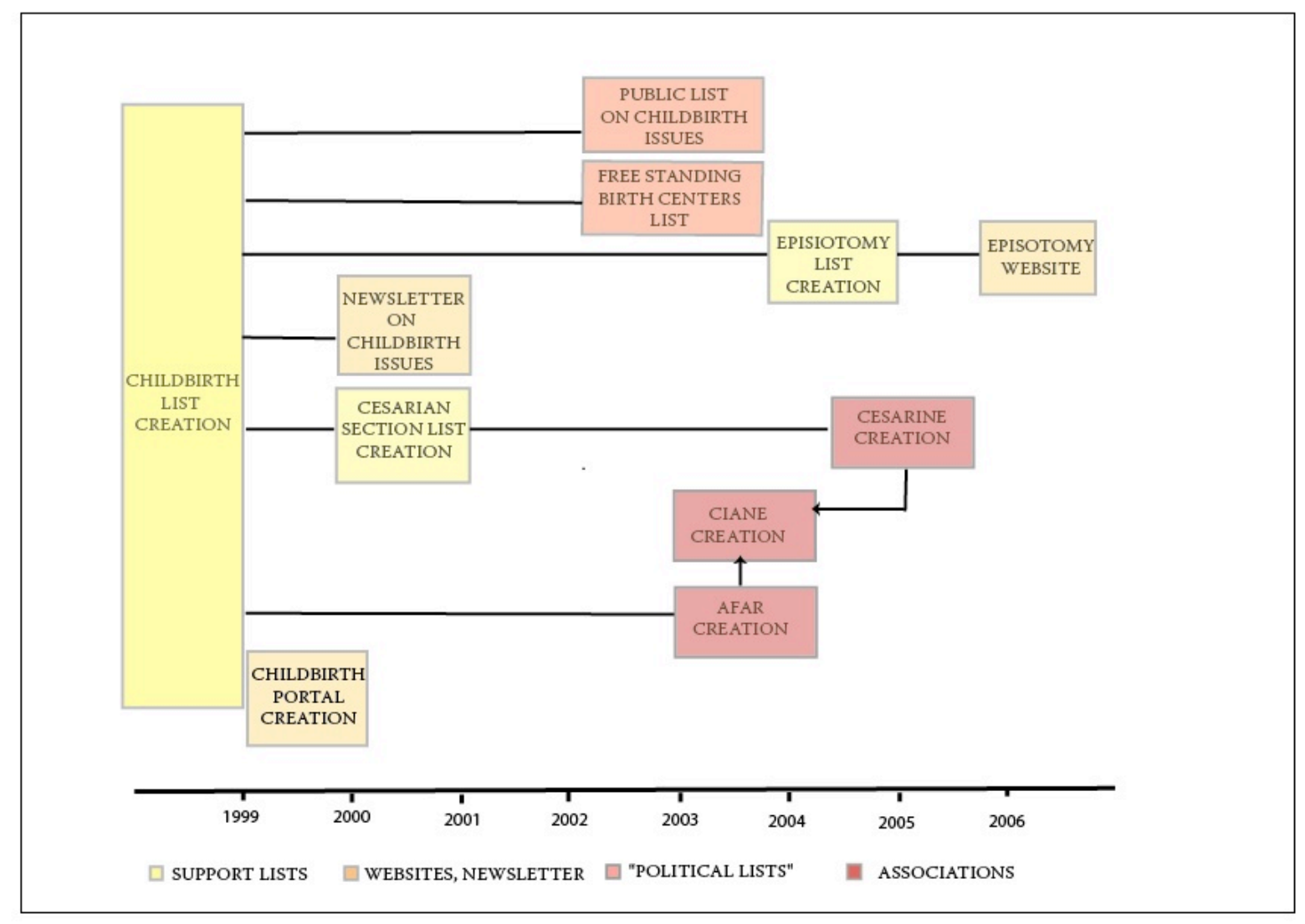

AFAR: Alliance Francophone pour l'Accouchement Respecté

CIANE: Collectif Interassociatif Autour de la NaissancE

These different groups ${ }^{17}$ form a tight network, as shown on the following chart: one third of the members of the discussion list that serves to coordinate the CIANE belongs or has belonged to one or several other groups. As a result, messages circulate regularly from one list to another and reflection topics can be launched simultaneously on two lists: again, the fact that a significant part of these groups works through electronic exchanges renders their relationships more fluid.

17 For more information, see their websites: Cesarine: http://www.cesarine.org/, AFAR : http://afar.naissance.asso.fr/; Episiotomy website: http://sites.google.com/site/infoepisio/; CIANE : http://ciane.naissance.asso.fr/. 


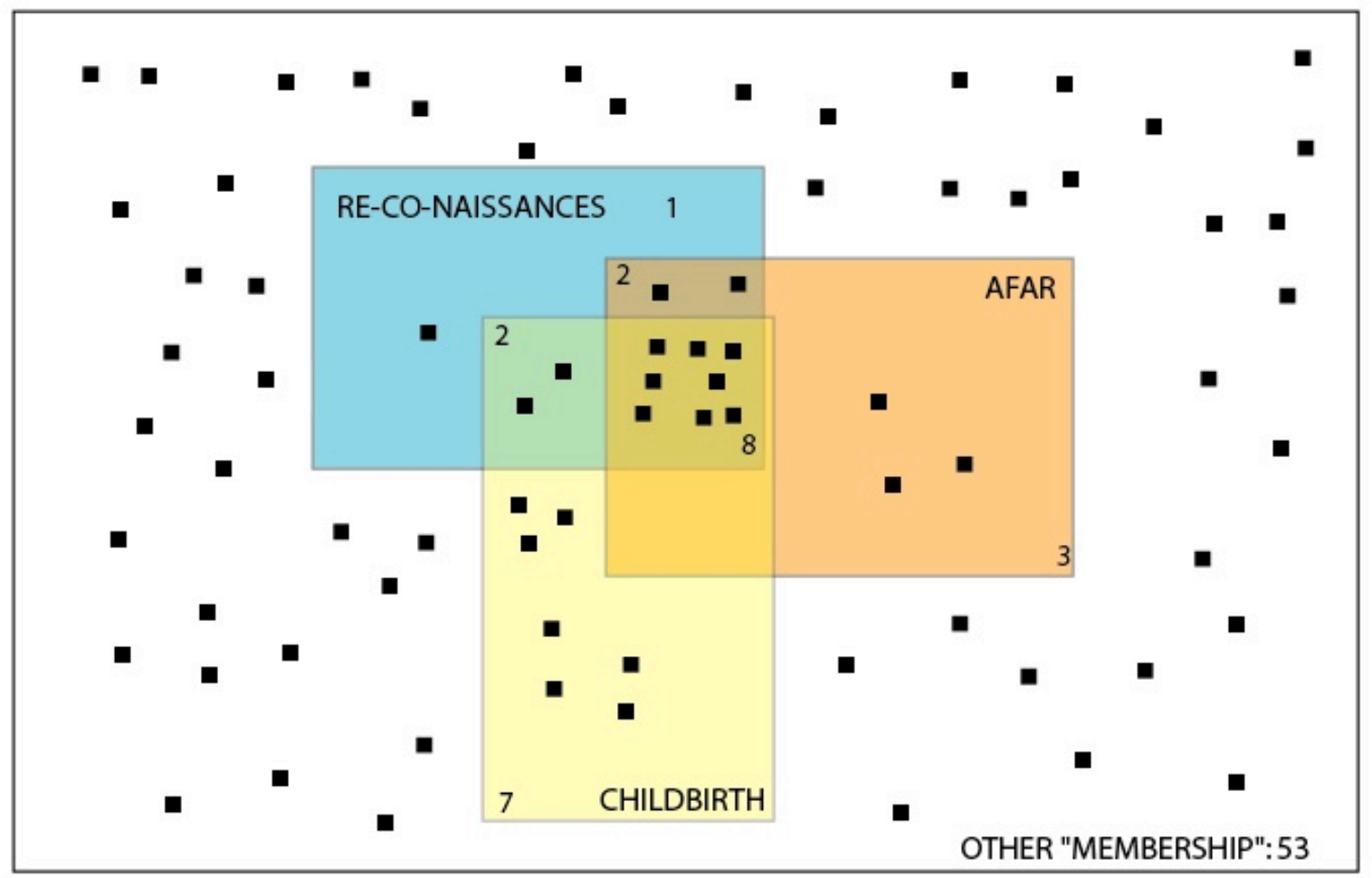

PARTICIPANTS' MEMBERSHIP ON THE CIANE LIST

In what follows, we will show that the collectives having emerged from these communities of practice form an epistemic community, i.e., constitute a network sharing both general policy options and a certain knowledge basis. We will focus on two of these groups, AFAR (Alliance Francophone pour l'Accouchement Respecté) and CIANE (Collectif Interassociatif Autour de la NaissancE), which play a key role in the establishment of this articulation between science and policy. As we will see, AFAR is better defined as an agent that fosters further mobilizations: it offers the general public, individuals and various childbirth movements tools and support, allowing them to appropriate medical knowledge in order to use it in defending their points of view. CIANE positions itself more as the users' representative, and as such as the interlocutor for other stakeholders, i.e. governments, health professionals, researchers, social security. We then see how action on childbirth policies results from these groups' complementary activities.

\section{AFAR, APPROPRIATING MEDICAL KNOWLEDGE}

The Alliance Francophone pour l'Accouchement Respecté was born on a whim: one of the founders of the Childbirth list suggested organizing - on the model of the World Breastfeeding Week organized since 1997 - a World Respected Childbirth Week (WRCW) and created an association to support this event. Six weeks later, in May 2003, the association was declared as a legal entity and its objectives were defined as follows:

Considering that women and couples no longer have a choice as to labor; considering it has become a hyper-medicalized act for all, considering it is a special moment in a woman's life, in a couple's life which - what is more generates rights, AFAR informs about possible choices and acts to defend individual rights. AFAR has no theory or dogma to disseminate and is completely free and independent from any medical, religious or political school or doctrine. 
As evidenced by this paragraph, the orientation its creators intend to give this association is a direct extension of positions taken during discussions around the Childbirth site. Although among its members there were some of the most active 'childbirth' list contributors - and namely some of its founders - this association was not simply for the concretization of a project that was there from the beginning, five years before. The statement of the goals themselves and the means by which the AFAR equips itself largely results from the collective learning the 'childbirth' list has experienced, from the principle of 'a choice open to parents' to 'the importance of information that has to be as fair as possible and include the medical aspects'. The means by which the association equips itself are diverse: dissemination of information (documents, conferences), mobilization around an event (World Respected Childbirth Week), but also positioning itself as a legal actor (filing civil actions for lawsuits), establishing contacts between users and professionals that are open to more varied demands than those accepted by maternity wards, and constitution of a databank gathering the latest available medical information. The bibliographic database is one of the most important achievements of AFAR's work and includes over 2200 references, made available on a public website.

This bibliographical work is articulated around public events organized for the World Respected Childbirth Week which, each year, focuses on a particular theme: episiotomy the first year, then positions of delivery, time of delivery, caesarean section etc. All these issues refer to 'sticky points' in the organization of childbirth in France, and question the arguments on behalf of which professionals impose constraints on women.

While the 'childbirth' list was entirely dedicated to its members, AFAR is placed in an intermediary position: it seeks both to equip individuals with means to oppose a strong case to the whims of professionals, to assist individuals seeking legal compensation, and to alert public opinion on a certain number of issues. Yet, the lever for change lies at an individual level, and it is by collectivizing and publicizing cases - and especially by including them in a scientifically robust macro argument - that it is likely to operate.

\section{CIANE, INVESTING THE POLITICAL SPACE}

The creation of the Inter-Association Collective around Birth is contemporary with the creation of AFAR. It took place under special circumstances as professionals were organizing the États généraux de la naissance; it owed much to certain users' aspiration to participate in this event. Two individuals played a major role in canvassing all the various associations, groups and discussion lists concerned with these issues: one of them was a contributor to the 'childbirth' list and belonged to the AFAR founding group; the other one was an activist from an association of victims of medical accidents. As a result, people from different backgrounds, local associations, discussion lists, and large generalist organizations aggregated into an informal collective, founded with a clear activist perspective in mind. The collective set itself three major objectives: to inform, to identify improvement strategies, to communicate and be recognized as an interlocutor on behalf of users facing public authorities. Initially skeptical, several members of AFAR and the 'childbirth' list rapidly joined the group, which, again, revolved around a discussion list.

Through its expertise and contact network, CIANE rapidly gained a certain reputation among governments authorities, which led it to be repeatedly asked to represent users from various organizations in a historically favorable context: in fact, in 2002, a law imposed the presence of users' representatives in all health institutions, and CIANE's service offering appeared exactly at the right time, all the more because CIANE officials were promptly recognized for the seriousness of their actions. Although the situation is different from that described by 
Haas, it was also marked by a claim to participate in policymaking, a demand from the government authorities committed to the democratization of health.

CIANE's activity is therefore partly pulled by an external demand: participation in various groups, at the Ministry of Health, in health agencies, etc., proofreading and evaluating various documents such as best practice recommendations, the presentation of CIANE or its work to various professional organizations or during medical conferences, interviews with the media, writing articles for professional or academic journals etc. In addition, it also develops its own actions: it provides a significant watch on publications of all sorts dealing with perinatal issues and makes a point to produce the appropriate counter-arguments, especially by publishing statements or position papers about matters relating to the organization of health care; it sparked off debates by organizing the new États généraux de la naissance in 2006.

All these activities rely heavily on the collection, analysis, diffusion and production of written texts; the work is well adjusted to the means available: the group can rely on resources accumulated both on the childbirth portal and in the AFAR database. An ordinary work group sequence starts with a message calling attention to an article, a report, an event etc. The message can generate a short exchange, allowing the group to complete and comment the information, or a longer debate leading to the idea of a necessary reaction from the group. At this point of the discussion - thanks to the medium used - arguments have already been exchanged in a written format. When one of the participants suggests writing a first draft, this initiative takes place in a well-established collective process. The draft is then discussed, amended and the process is made easier by the fact that the comments and documents are technically similar. Finally, the collective production (a letter, the assessment of a report, an article, a position paper) is published or sent to its recipients. The continuity established through the electronic medium among information, production and dissemination plays a key role in the effectiveness of the group. Given both the group's means and the demands it faces, the activist work mostly consists in developing arguments; as we will see in the case of episiotomy, the problematization, the search for sources, the collection of testimonials - all of which allow for the construction of an argumentation - draw upon the circulation of people, documents and ideas among different groups.

\section{EPISIOTOMY OR THE EPISTEMIC COMMUNITY IN ACTION}

As mentioned above, the connections between the various groups that were born from the 'childbirth' list are numerous; but can they be considered an epistemic community? In other words, to what extent is the political work performed by CIANE supported by these interactions? The case of episiotomy is a good example of these mechanisms.

Episiotomy was a recurring theme in the 'childbirth' list: the word episiotomy is present in more than $7 \%$ of the messages. Shortly before the creation of AFAR, lengthy discussions took place, leading to the idea, ultimately not concretized, of a site intended to collect testimonials from women. Episiotomy appears indeed as an emblematic act as to the excesses of medicalization: routinely practiced by certain professionals without women's consent, the discussions on the list demonstrate that it can have a considerable impact on the physical, mental and sexual health of the women who have undergone it, yet its usefulness from the medical point of view is, as a minimum, controversial.

It is hardly surprising in this context that this was the first topic invested by AFAR: as already in fall 2003, soon after the creation of the AFAR, one of the members of the group, a professional scientist, began bibliographical work. She collected articles published in 
international medical journals on the subject, with the idea of supporting the positions AFAR would take, or even that of contributing to the files of women wishing to take legal action after an episiotomy. Two documents arose from this work: a 76-page compilation, which uses 93 of the 158 references included in the database in May 2004, provides a summary for each article and highlights the most important passages for ease of understanding, a 2-page synthesis presents the most significant articles. AFAR decided at the same time to make episiotomy the theme of the first World Respected Childbirth Week in May 2004. Simultaneously, the idea of creating a support list around episiotomy arose.

In autumn 2004, based on the work done by AFAR, CIANE suggested to ANAES (the French National Agency for Accreditation and Evaluation in Health) episiotomy as a theme for the development of clinical practice recommendations, having previously secured the support of the National College of French Gynecologists and Obstetricians (CNGOF). CNGOF decided to adopt this initiative and make it its own, developed recommendations in 2005 and then consulted CIANE.

CIANE formed a work group and produced a detailed proposal on these recommendations in the form of a 15-page letter, highlighting these recommendations' advantages but also their shortcomings. The CNGOF text was almost exclusively technical, based on the medical literature, and concluded briefly with a number of very general policy recommendations. Conversely, the work produced by CIANE used also used testimonials gathered among women, particularly from the support list on episiotomy. The list generated alternate approaches to procedures and hosted a debate between members of the work group that belonged all three lists (CIANE, AFAR and "Childbirth").In addition, it sought to reframe the problem - away from the 'prevention' of episiotomy and towards discussion of perineal lacerations. This 'semantic shift', as it was described in the text opened up other policy options. ,

CIANE's text took the same stand as CNGOF's: the practices' medical relevance was evaluated by resorting to medical literature. But it involved other evaluation methods, integrating the point of view of those concerned. It therefore led to further and more varied recommendations: women's consent, professional training, medical protocols for the 'management of labor'. CIANE expressed rather severe criticism as to the $30 \%$ rate of episiotomies that was stated as an objective by CNGOF; according to CIANE, this objective was not based on rational arguments, and was too 'political' in the way it tried to be gentle with professionals.

The aim of the above analysis was not to be exhaustive but rather to show how CIANE's ability to become involved with health policies is supported by the diffuse action of an epistemic community, composed of groups among which individuals and discussions circulate and whose knowledge and forms of expertise are complementary.

REVISITING HAAS' EPISTEMIC COMMUNITIES

Considering the cases we examined in detail, it seems reasonable to think that these lay epistemic communities are created in response/to oppose other epistemic communities mainly formed by professionals, or at least groups that have a dominant position due to the authority conferred on them by knowledge. We have similarly studied the case of obstetrics and the way it focuses on pathology (Akrich \& Pasveer 1996), which largely predetermines the definition of relevant knowledge and the acceptable forms of health care management. 
The same could be said of the way the imprint of psychoanalysis on French psychiatry determines the treatment of autism (Méadel 2006). Endometriosis treatment in the United States (Capek 2000) was also 'framed' by a sexist interpretation that tilted medical care management. In all these cases where users/patients disagree with the way medicine treats an issue that matters to them, it seems they are forced to elaborate a competing politicoscientific argumentation that makes possible redefining the problems at stake, the relevant knowledge, the skills and prerogatives of patients and professionals alike, all these elements forming a hopelessly entangled ball of string. ${ }^{18}$ Unlike epistemic communities as defined by Haas, these communities have no hegemonic position in the elaboration of public policies. On the contrary, they appear as opposing forces facing professional epistemic communities and reopen the range of possibilities, which professionals tended to limit and keep under their control.

Our analysis raises another point of discussion in relation with Haas' work: to him, it is clear that epistemic communities on one side and activist groups on the other refer to separate realities that one can yet compare: epistemic communities and social movements demonstrate certain similarities, particularly because both are based on 'normative beliefs' that guide and give a meaning to their political action.

Even so, while epistemic communities rely both on a common knowledge basis and on a convergent representation of the world concerned with the issues at stake, interest groups and social movements do not - in Haas' opinion - display the same homogeneity. An epistemic community would always place supporting scientific knowledge at the forefront of its requirements: otherwise, the epistemic community would give up participating in the political process; conversely, the possible use of such support would be, for interest groups or social movements, purely instrumental. In fact, epistemic communities would have an exclusive relationship to knowledge and especially a very strong inclination to articulate both policy proposals and knowledge: because of this assumption, the description suggested by Haas (1992a) has a moral undertone.

As previously noted (Barthe \& Gilbert (2005)), the 'scientifization' of politics, which occurs through recourse to scientific expertise, is often accompanied by a movement towards the 'politicizing' of science: where political positions appear to rely strongly on the mobilization of experts, their opponents aim to constitute a counter-expertise. Consequently, the border between epistemic communities and advocacy groups is a bit more difficult to establish.

\section{CONCLUSION}

The first part of this article enabled us to see that discussion lists gathering people concerned by the same health issue can be considered as communities of practice involved in a form of collective learning that made it possible to develop experiential knowledge and to articulate this knowledge with other knowledge sources. This articulation is possible and

${ }^{18}$ In other cases which we could only briefly evoke here - including emerging or poorly recognized diseases - the question arises somewhat differently: the point is more to raise the medical world's interest and gain recognition for the disease rather than to fight against an existing treatment method - even though, in fact, patients can consider themselves victims of misunderstanding, or even of a stigmatizing attitude on behalf of physicians. Their concerns are more exclusively medical, and though their investment as related to knowledge is important, it connects differently to the policy question. 
even actively sought, particularly because the experiential knowledge in question is not a subject's intimate knowledge relating to him/herself, it integrates and questions the relationship between personal experience and its interactions with the medical world. In other words, medicine is already involved with what is considered as 'experience' and the problematization put forward by the list often consists in deconstructing the connections between these two poles. In a number of cases, this collective learning leads to the production of documents, bibliographies, corpuses and links; their frequent publicization commits the list to a first political work.

In the second part, we showed how these communities of practice could give rise to new groups whose activities no longer focus on their members as they previously did. As these groups are committed to an activist approach, their activities are thus oriented towards the outside world. The way these groups are constituted and the resources on which they can rely are elements that contribute to their transformation into actual epistemic communities, i.e. communities whose positioning is to be found at the articulation between science and policies. Unlike Haas' epistemic communities, these do not gather individuals initially recognized for their expertise. However, their ability to influence the content of policies while preserving users' point of view is quite directly related to their ability to incorporate their claims into a scientifically sound argumentation.

Using the concept of epistemic community to describe certain movements such as described above makes possible highlighting specific forms of activism akin to embodied health movements (EHM). Yet, they seem to distinguish themselves from the forms described by Brown et al. (2004) by the position they grant to medical and scientific knowledge: these are not pathways towards improving people's state; instead, they are argumentative resources that allow deconstructing professionals' positions and practices. Whereas in one case, science is likely to provide answers to activists' claims, in the other it is the language into which the claims have to be translated in order to be heard. We could but sketch in this article the task that consists in specifying forms of knowledge and determining the respective part they play in activist movements; this is an issue that undoubtedly deserves to be analyzed in more detail.

AKRICH, M. and MÉADEL, C. (2002) 'Prendre ses médicaments/prendre la parole : les usages des médicaments par les patients dans les listes de discussion électroniques', Sciences Sociales \& Santé, Vol. 20, No. 1, pp. 89-116.

$\mathrm{AKRICH}, \mathrm{M}$. and MÉADEL, (2007) 'De l'interaction à l'engagement : les collectifs électroniques, nouveaux militants de la santé', Hermès, Vol. 47, pp. 145-153.

AKRICH, M. and MÉADEL, C. (forthcoming) 'Policing exchanges as self description in internet groups', In Eric, B., Cécile, M. and Meriem, M. (eds.) The regulation of Internet: Cambridge: Cambridge University Press.

AKRICH, M. and PASVEER, B. (1996) Comment la naissance vient aux femmes. Les techniques de l'accouchement en France et aux Pays-Bas. Paris: Les Empêcheurs de penser en rond.

AKRICH, M. and PASVEER, B. (2004) 'Embodiment and Disembodiment in Childbirth Narratives', Body \& Society. Special Issue on Bodies on Trial., Vol. 10, No. 2-3, pp. 63-84. 
AMIN, A. and COHENDET, P. (2004) Architectures of Knowledge: Firms, Capabilities, and Communities. Oxford: Oxford University Press.

AMIN, A. and ROBERTS, J. (2008) 'Knowing in action: Beyond communities of practice', Research Policy, Vol. 37, No. 2, pp. 353-369.

ANGLIN, M. (1997) 'Working from the inside out: implications of breast cancer activism for biomedical policies and practices', Social Science \& Medicine, Vol. 44, No. 9, pp. 1403-1415.

ARKSEY, H. (1994) 'Expert and Lay Participation in the Construction of Medical Knowledge', Sociology of Health \& IIIness, Vol. 16, No. 4, pp. 448-468.

BARBOT, J. (2002) Les malades en mouvements : la medecine et la science a l'épreuve du sida. Paris: Balland.

BARTHE, Y. and GILBERT, C. (2005) 'Impuretés et compromis de l'expertise, une difficile reconnaissance. À propos des risques collectifs et des situations d'incertitude', in Dumoulin, L., LaBranche, S., Robert, C. and Warin, P. (eds.) Le recours aux experts. Raisons et usages politiques, Grenoble: Presses universitaires de Grenoble, pp. 43-62.

BAYM, N.K. (2000) Tune In, Log On: Soaps, Fandom, and Online Community. London: Sage.

BEL, B. (2005) 'Personal and Social Communication: Two Instances of Electronic Mail', in Bel, B., Brouwer, J., Das, B., Parthasarathi, V. and Poitevin, G. (eds.) Communication Processes, 1: Media and Mediation., New Delhi/Thousand Oaks/London: Sage.

BOLAND, R. J. Jr., \& TENKASI, R. V. (1995). Perspective Making and Perspective Taking in Communities of Knowing. Organization Science, Vol. 6, No. 4, pp. 350-372.

BORKMAN, T. (1976) 'Experiential Knowledge: A New Concept for the Analysis of Self-Help Groups', The Social Service Review, Vol. 50, No. 3, pp. 445-456.

BORKMAN, T. (1999) Understanding Self-Help/Mutual Aid: Experiential Learning in the Commons. New Brunswick and London: Rutgers University Press.

BROWN, P., ZAVESTOSKI, S., MCCORMICK, S., MAYER, B., MORELLO-FROSCH, R. and ALTMAN, R.G. (2004) 'Embodied health movements: new approaches to social movements in health', Sociology of Health \& Illness, Vol. 26, No. 1, pp. 50-80.

CALLON, M., LASCOUMES, P., \& BARTHE, Y. (2009) Acting in an Uncertain World. An Essay on Technical Democracy, Cambridge: MIT Press.

CAPEK, S. (2000) 'Reframing Endometriosis: From "Career Woman's Disease" to Environment/Body Connections', in Kroll-Smith, S., Brown, P. and Gunter, V.J. (eds.) IIIness and the Environment. A Reader in Contested Medicine, New York and London New York University Press, pp. 72-91.

COLLINS, H.M. and EVANS, R. (2002) 'The Third Wave of Science Studies: Studies of Expertise and Experience', in Social Studies of Science, Vol. 32, No. 2, pp. 235-296.

DUMIT, J. (2006) 'Illnesses you have to fight to get: Facts as forces in uncertain, emergent illnesses', Social Science \& Medicine, Vol. 62, No. 3, pp. 577-590.

EPSTEIN, S. (1995) 'The Construction of Lay Expertise: AIDS Activism and the Forging of Credibility in the Reform of Clinical Trials', Science, Technology \& Human Values, Vol. 20, No. 4, pp. 408-437. 
HAAS, P.M. (1992a) 'Banning Chlorofluorocarbons: Epistemic Community Efforts to Protect Stratospheric Ozone', International Organization, Vol. 46, No. 1, pp. 187-244.

HAAS, P.M. (1992b) 'Introduction: Epistemic Communities and International Policy Coordination', International Organization, Vol. 46, No. 1, pp. 1-35.

JOSEFSSON, U. (2005) 'Coping with illness online: The case of patients' online communities', The Information society, Vol. 21, No. 2, pp. 143-153.

KLING, R. and COURTRIGHT, C. (2003) 'Group Behavior and Learning in Electronic Forums: A Sociotechnical Approach', Information Society, Vol. 19, No. (3), 221.

LAVE, J. and WENGER, E. (1991) Situated Learning. Legitimate peripheral participation. New York: Cambridge University Press.

LOADER, B.D., MUNCER, S., BURROWS, R., PLEACE, N. and NETTLETON, S. (2002) 'Medicine on the line? Computer-mediated social support and advice for people with diabetes', International Journal of Social Welfare, Vol. 11, No. 1, pp. 53-65.

MÉADEL, C. (2006) 'Le spectre "psy" réordonné par des parents d'enfant autiste. L'étude d'un cercle de discussion électronique', Politix, 19, pp. 52-82.

PETERSON, M.J. (1992) 'Whalers, Cetologists, Environmentalists, and the International Management of Whaling', International Organization, Vol. 46, No. 1, pp. 147-186.

RABEHARISOA, V. and CALLON, M. (2000) 'Les associations de malades et la recherche. I. Des self-help groups aux associations de malades', médecine/sciences, Vol. 16, No. 8-9, pp. 945-949.

WEINER, L.Y. (1994) 'Reconstructing Motherhood: The La Leche League in Postwar America', The Journal of American History, Vol. 80, Vol. 4, pp. 1357-1381. 